\title{
Supervision and control of working fixtures position of the single bucket excavator with regard to displacement of their undercarriage and outriggers' characteristics
}

\author{
Adam Bartnicki*, Stanisław Konopka*, Franciszek Kuczmarski*, Andrzej Typiak*, \\ and Józef Wrona* \\ * Military University of Technology, Institute of Machinery Construction \\ ul. KALISKIEGO 2, 01-489 WARSAW, POLAND, phone (48 22) 6859419
}

\begin{abstract}
In automatic control process of a single bucket excavators' work the problem of taking the assumed trajectory by working fixtures is very important.

In this paper are described the method of such measurements and the system for positioning of the bucket cutting edge with using the laser beam assumed to be the relation position has been presented.
\end{abstract}

\section{INTRODUCTION}

In automatic control process of a single bucket excavators' work the problem of taking the assumed trajectory by working fixtures, particulary the cutting edge of the bucket is very important. In the stage execution of excavation it is indispensable to keep the assumed profile of excavation. That concerns guidance of the bucket cutting edge and working fixtures along the safe trajectory while manoeuvring working fixture. That ought to be the optimum trajectory (in the sense the accepted valuation coefficient).

Because position of cutting edge of a single bucket excavators can not measure in direct way you ought to make measurement of indirect quantities and after theirs converting transmit them to control device.There are compared with assumed quantities and on the ground of it there are elaborated control signals.

Due to the changies of subsoil/ground profile along which the excavator (fig. 1) is relocated and displacement of outrigger during excavation (with stable arrangement of machine - fig. 2). They essentially influence the position of the working tool and the vertical displacement of the cutting edge [4,5] which are caused by them and they are compariable with admissible total error in their position $\Delta z=5-10 \mathrm{~cm}$ (fig.3).

Hence to guide the cutting edge of the bucket along the assumed trajectory the control system must possess an ability qualification of the bucket position in stationary coordinate system.

Simultaneously the way of control of the bucket cutting edge position depends on the character of coupling of outrigger (stiffening leg) and subsoil defined by forces and displacements at point of support.

Because technological tasks (cordinates of excavation position, optimum trajectories, etc.) are given in geodesic (external) coordinate system, for guidance of bucket cutting edge along assumed trajectory, the measurement system which is mounted on excavator must possess an ability to qualification of the bucket position in this coordinate system. 

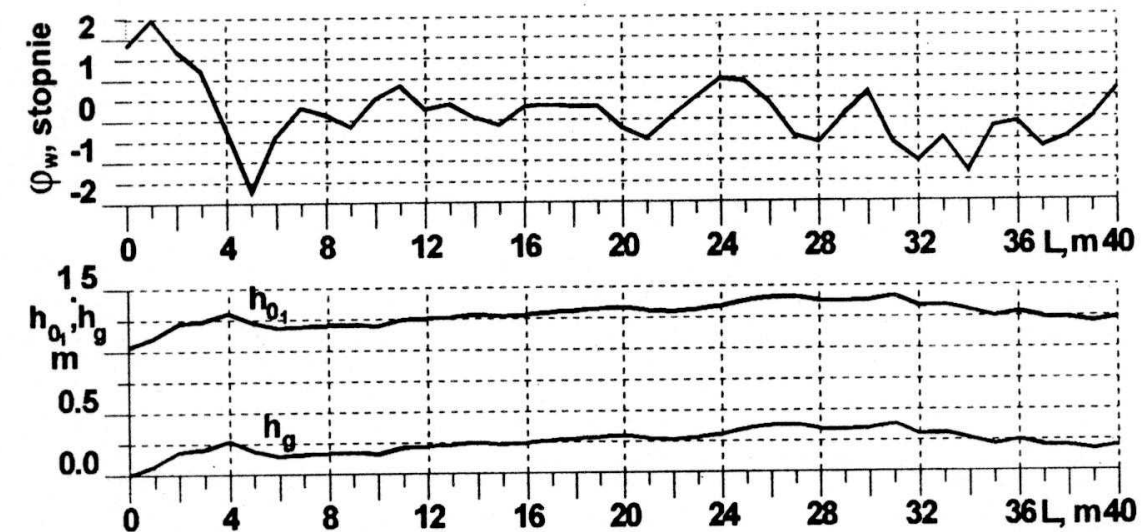

Figure 1 Lenghtwise tilts and vertical displacements of excavator's body in function of excavation lenght L: $\varphi_{w}$ - angle of lenghtwise tilt of body, $h_{g}$ - co-ordinate qualifying of subsoil profile, $\mathrm{h}_{01}$ - co-ordinate qualifying of position of excavator's rotation rim
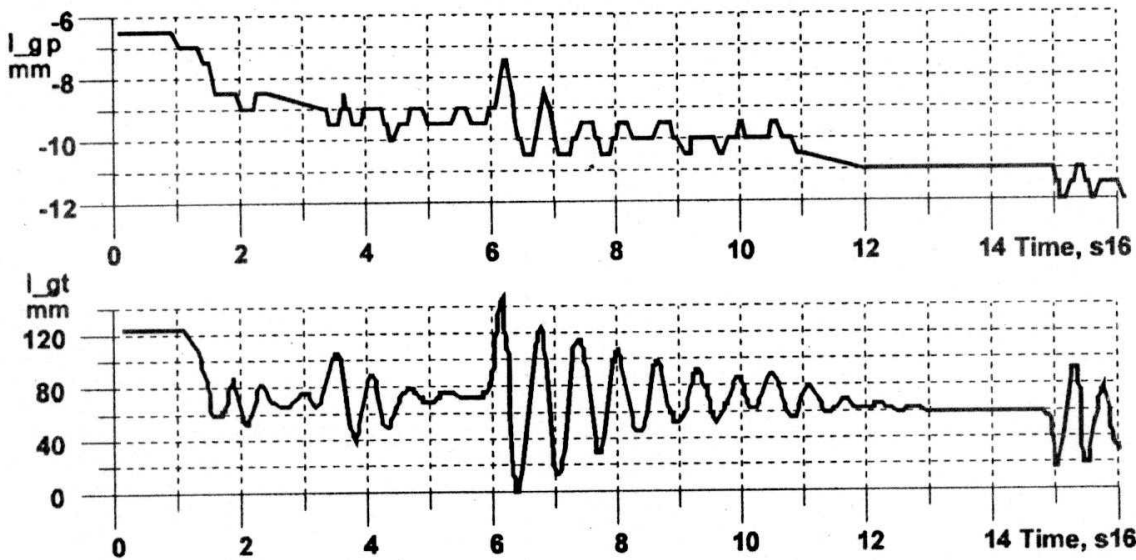

Figure 2 Displacement of two points of machine's undercarriage in single works cycle during excavating

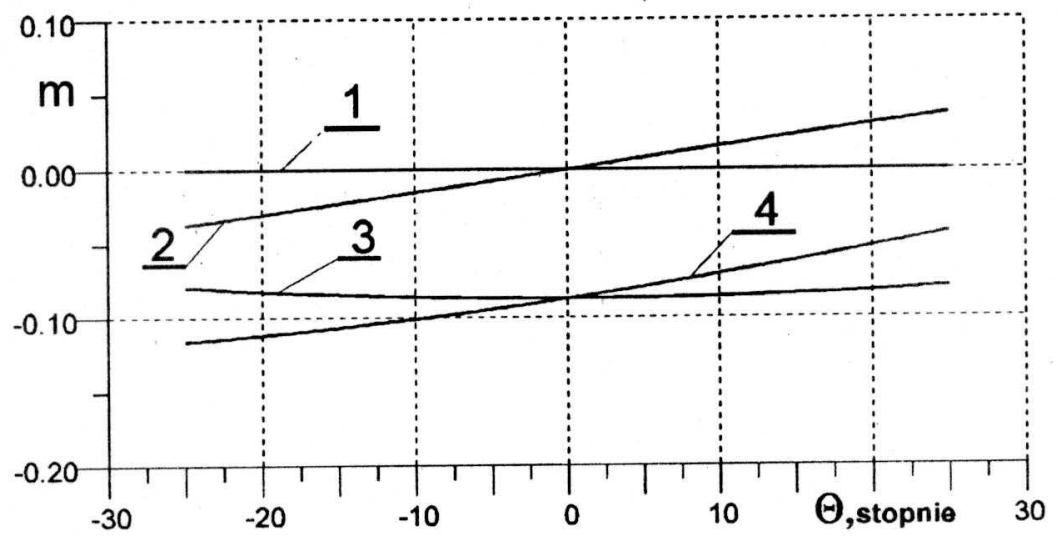

Figure 3 Vertical coordinates of bucket's cutting edge centre in function of body rotation angle $\Theta$ for different values of lenghtwise tilt angles $\varphi_{\mathrm{w}}$ (around axle $0_{\mathrm{x}}$ ) and crosswise $\varphi_{\mathrm{p}}$ around axle $0_{\mathrm{y}}$ ): $1-\varphi_{\mathrm{p}}=0^{\circ}, \varphi_{\mathrm{W}}=0^{\circ} ; 2-\varphi_{\mathrm{p}}=1^{\circ}, \varphi_{\mathrm{W}}=0^{\circ} ; 3-\varphi_{\mathrm{p}}=0^{\circ}, \varphi_{\mathrm{w}}=1^{0} ; 4-\varphi_{\mathrm{p}}=1^{\circ}, \varphi_{\mathrm{W}}=1^{\circ}$ 


\section{IDEA OF MEASUREMENT OF CUTTING EDGE POSITION.}

The considerations above give indication univocal there can not measure (to qualify) position of working fixtures in coordinate system bound up with excavators body. Qualification of cutting edge of bucket position in coordinate system $\eta^{\prime} C^{\prime} \xi^{\prime}$ is necessary.

Taking into consideration problem precise measurement vertical co- ordinate of cutting edge (fig.4), we can obtain:

$$
z_{r}=z_{c}+l_{c D} \cdot \sin \left(\alpha_{1}+\alpha\right)+l_{D B} \cdot \sin \left[\left(\alpha_{1}+\alpha\right)+\beta\right]+l_{B g} \cdot \sin \left[\left(\alpha_{1}+\alpha\right)+\beta+\delta\right]
$$

where: $z_{C}=\overline{C C^{\prime \prime}}$ - vertical co - ordinate point $\mathrm{C}$ (articulated backhoe - body joint), $\alpha_{1}, \beta, \delta$ angles of working fixtures position in local coordinate system $\eta^{\prime \prime} C \xi^{\prime \prime}, \alpha$-angle of roll (inclination) of excavators body in symmetry plane of working fixtures.

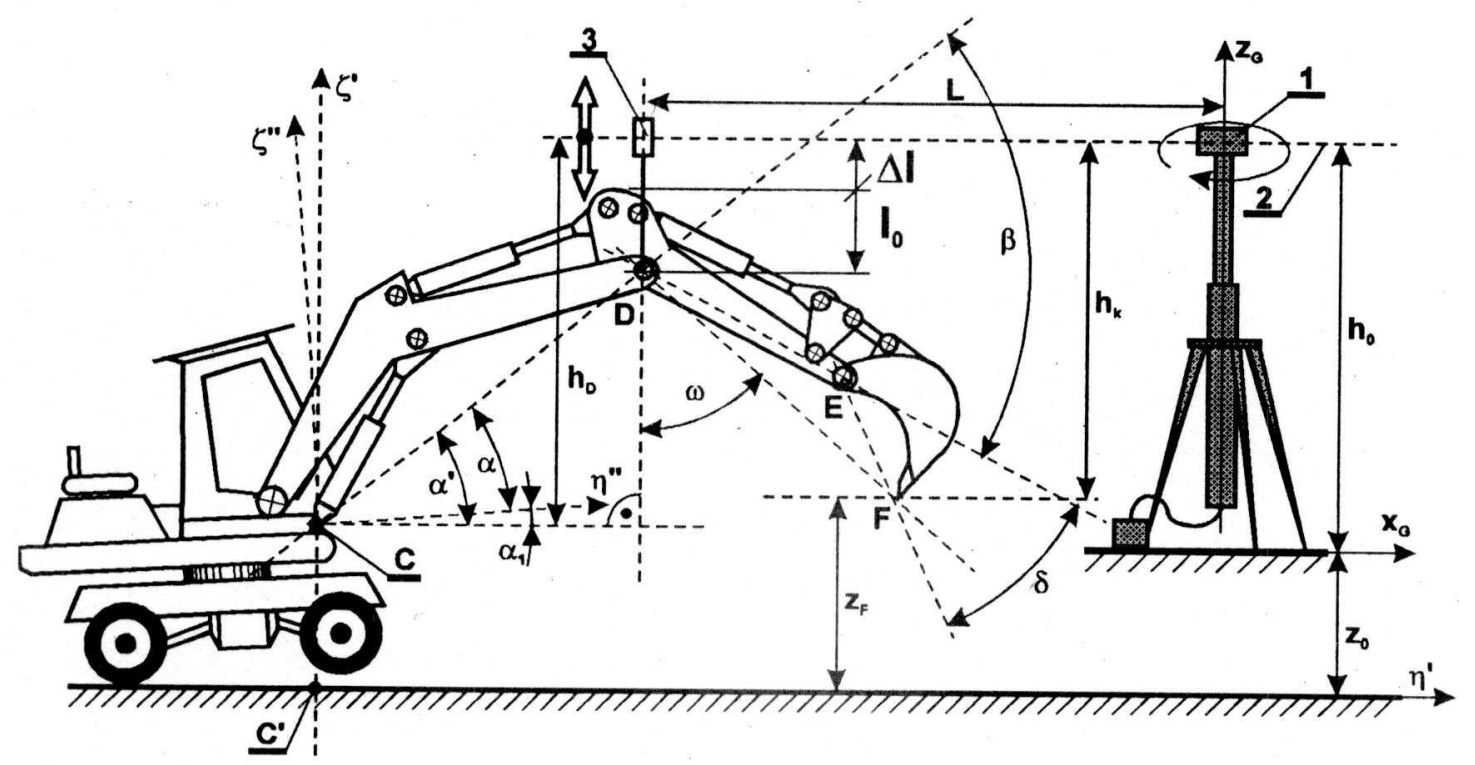

Figure 4 Scheme of measurement of bucket cutting edge with make using rotating laser beam as datum plane: 1 - laser transmiter, 2 - rotating laser beam, 3 - detector of laser beam

As result from equation (1) to qualify the co - ordinate $z_{F}$ of cutting edge the measurement of five quantities $z_{c}, \alpha^{\prime}, \alpha_{1}, \beta, \delta$ is necessary. The angles $\alpha^{\prime}, \alpha_{1}$ can be measured together (sum) in the stationary coordinate system (from the gravitation level; $\alpha=\alpha^{\prime}+\alpha_{1}$ ). Error of qualification (definition) of co - ordinate $z_{p}$ can be written as :

$$
\Delta z_{r}=\frac{\partial z_{p}}{\partial z_{c}} \cdot \Delta z_{c}+\frac{\partial z_{r}}{\partial \alpha} \Delta \alpha+\frac{\partial z_{p}}{\partial \beta} \Delta \beta+\frac{\partial z_{p}}{\partial \delta} \Delta \delta
$$

Hence 


$$
\begin{aligned}
& \Delta z_{r}=\Delta z_{c}+\left[l_{c D} \cdot \cos \alpha+l_{D B} \cdot \cos (\alpha+\beta)+l_{B F} \cdot \cos (\alpha+\beta+\delta)\right] \Delta \alpha+ \\
& +\left[l_{D s} \cdot \cos (\alpha+\beta)+l_{B r} \cdot \cos (\alpha+\beta+\delta)\right] \Delta \beta+[\cos (\alpha+\beta+\delta)] \Delta \delta
\end{aligned}
$$

where: $\Delta z_{c}, \Delta \alpha, \Delta \beta, \Delta \delta$ - measurement precision of sensors.

As we can see this error depend on angles $(\alpha, \beta, \delta)$, so these are depended on working fixtures configuration. If we make assumption of allowable value $\Delta z$, in the ground on knowlegde of quantities run $z_{c}, \alpha, \beta, \delta=f(t)$ we can obtain the required measurement precision for sensors $\left(\Delta z_{c}, \Delta \alpha, \Delta \beta, \Delta \delta\right)$ and theirs sampling time $\Delta t_{x}, \Delta t_{\alpha}, \Delta t_{\beta}, \Delta t_{\delta}$. The way of calculation (evaluation) of these quantitiess you can find in $[2,4,5,6]$.

Using laser system to quality $\mathrm{z}_{\mathrm{C}}$ (measurement precision about $0,005 \mathrm{~m}$ in distance from transmitter about $0,02 \div 0,025 \mathrm{~m}$ ) is possible (using sensors measuring round angle with precision $2^{-14}$ - fourteen bits sensor).

\section{STRUCTURE OF SYSTEM CONTROLING POSITION OF SINGLE-BUCKET EXCAVATOR CUTTING EDGE WITH USING ROTATING LASER BEAM AS DATUM PLANE (ASSUMED LEVEL).}

Because qualifying of excavators bucket position in coordinate system (bounded with the machine) initiate too big errors of positioning there using external reference system is necessary. In earth-moving machines the rotating laser beam is generally used for it.

Description of building and operation (functioning) of laser system for limitation (restrictive) depth of digging are presented in [1].

That solution was presented on Twelfth International Symposium on Automation and Robotics in Construction ISARC'95 in Warsaw within special show which has organized by the host of conference.

Instead on fig. 4 scheme of system where detectors of rotating laser beam has been mounted in the boom (backhoe) - arm (stick) joint of the excavator's fixtures (point D) is presented. Detectors moves (translocate) along mast depend on angle $\omega$ :

$$
\Delta l=l_{D p}(1-\cos \omega)
$$

Simultaneously the execution system controls boom motion in such way to detectors (3) permanently set in axle of laser beam (2). It makes realization of horizontal motion of bucket's cutting edge possible.

System simplifies when we assume that bucket's angle of inchimation $\delta=0$. In this case you can extort (constrain) detector's motion by cam mechanism and then measurement and qualifying angles $\delta, \beta, \omega$ aren't needed. In consideration of cutting angle $\gamma$ lenght of line's segment on which may be realized horizontal motion of bucket's cutting edge is limited (restricted). That is about $25 \mathrm{~m}$ ( $40 \%$ field of work below subsoil level) for excavator with capacity $0,4 \mathrm{~m}^{3}$.

This system was researched (tested) on Polish single excavator K-406Al (wheel undercarriage). There has used control system for controling which is presented in [1].

Detectors aberration from laser beam axle more than $\pm 0,5 \mathrm{~cm}$ generates error signal on the ground of it there is elaborated signal controling the excavator's boom motion.

Examplary results of resarches are presented on fig. 5 . 


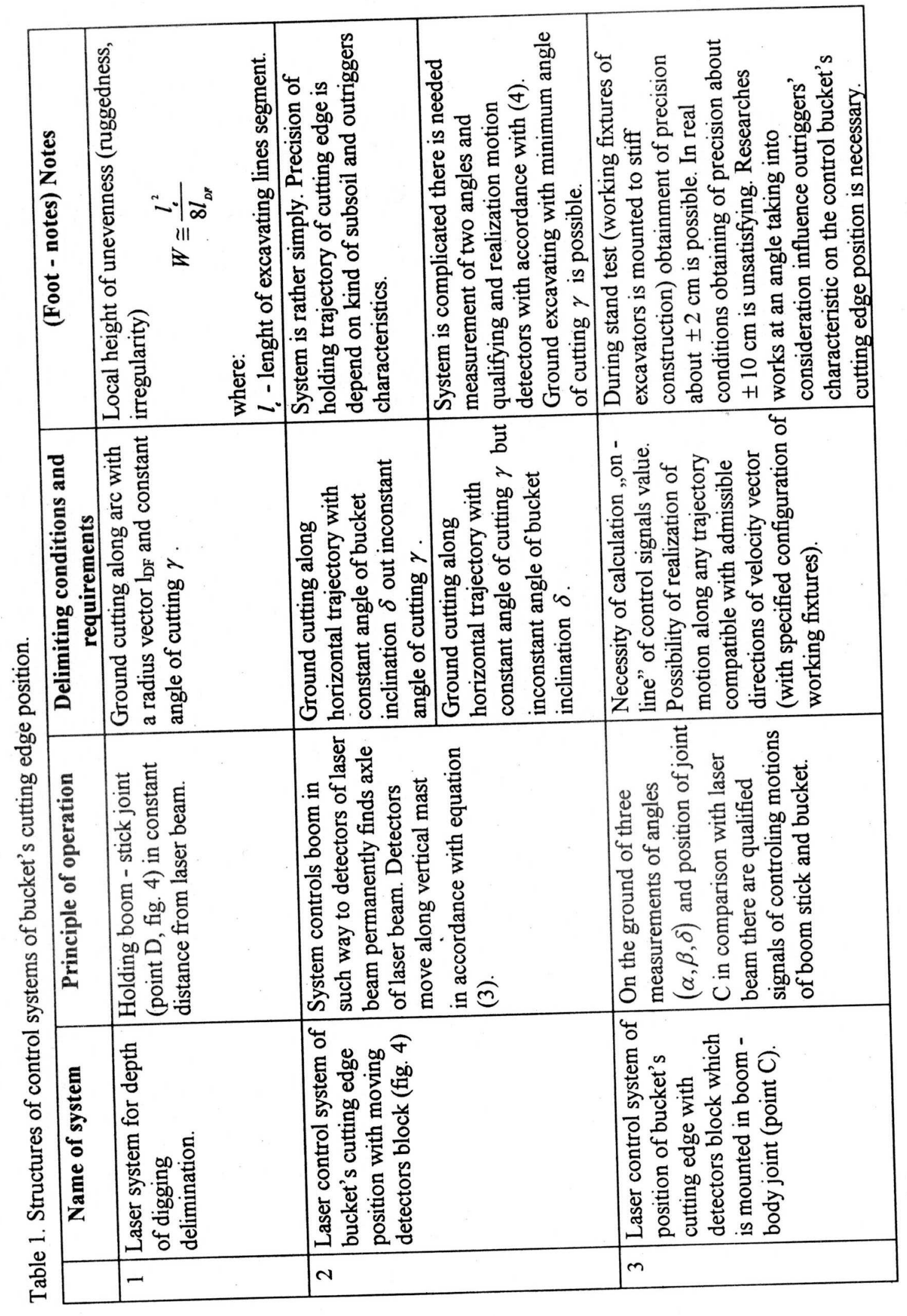




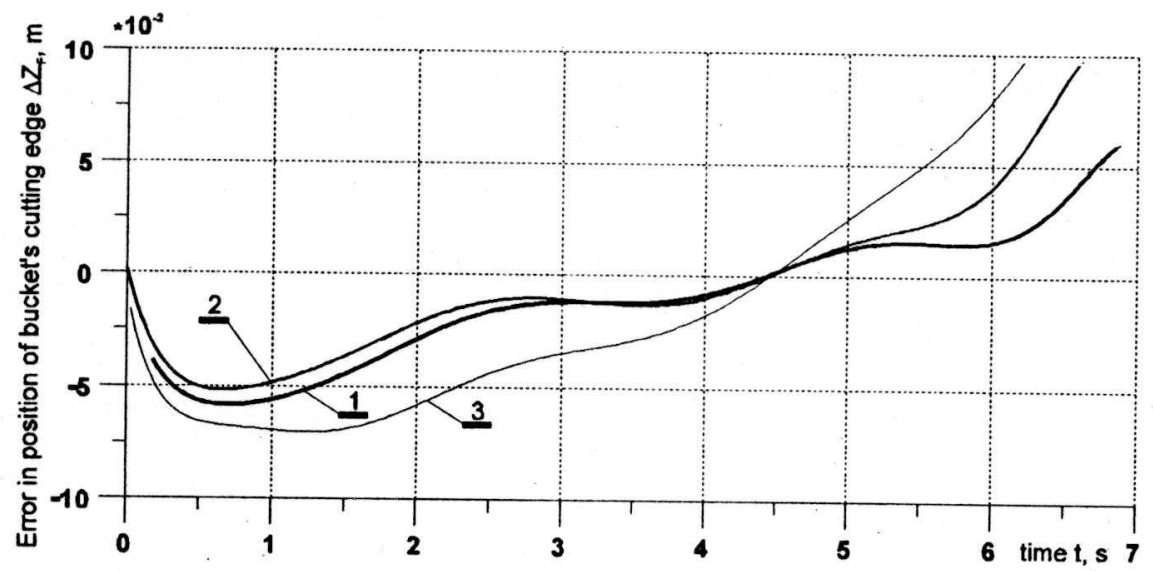

Figure 5 Dependence of error in position bucket's cutting edge $\Delta z_{F}$ from time of excavating phase for different control signals (curres $1,2,3$ )

On the ground of realized researches we can ascertain that selection (choice) of control signals in essential way depend on outriggers characteristics of machine.

Hence, knowledge of outriggers characteristics and kind of subsoil during shaping (forming) controls procedures is indispensable

Within summary in the table 1 characteristics three basic variants of solution of system for motion realization of buckets cutting edge along assumed curve are presented.

\section{REFERENS}

[1] A.BARTNICKI, S.KONOPKA, F.KUCZMARSKI, A.TYPIAK, J.WRONA, Computeraided work the operator of the single-bucket excavator with the remote control and laser control system of position, 12th ISARC'95 Twelfth International Symposium on Automation and Robotics in Construction. Warszawa 1995.

[2] J. BIALY , F. KUCZMARSKI , Pomiary w maszynie roboczej jako obiekcie sterowania. Metody doświadczalne ... Wrocław, Szklarska Poręba, 1993.

[3] L. PŁONECKI , J. CENDROWICZ, O zastosowaniu czujników położenia i kąta w układach sterowania osprzętem maszyn roboczych. IV Konferencja Maszyn Włókienniczych i Dźwigowych. Bielsko-Biała, 1993.

[4] F. KUCZMARSKI , Badania gassienicowych koparek hydraulicznych $z$ osprzętem podsiębiernym pod kątem możliwości zwiększenia dokładności wykonywania prac ziemnych. Rozprawa doktorska. Warszawa - WAT, 1983.

[5] F.KUCZMARSKI, A.TYPIAK, Pomiary położenia krawędzi skrawającej łyżki koparki jednonaczyniowej. Metody doświadczalne ... Wrocław, Szklarska Poręba, 1995.

[6] K. MAŃCZAK , Metody identyfikacji wielowymiarowych obiektów sterowania. Warszawa, WNT 1970. 